\title{
SOCIEDADE, NATUREZA E DESENVOLVIMENTO: ABORDAGEM BIBLIOGRÁFICA
}

Jadson de Jesus Santos ${ }^{1}$ Phellipe Cunha da Silva ${ }^{2}$

\section{RESUMO}

O presente trabalho, apresentado em forma de resenha crítica comparativa, tenta abordar a relação entre sociedade, natureza e o desenvolvimento elaborado pelo homem. A abordagem será dada em duas etapas: a primeira abordando a sociedade e o desenvolvimento, correlacionando ideias de autores de diferentes épocas; e a segunda, uma abordagem entre a natureza e desenvolvimento. A abordagem dos temas é de cunho impessoal, retratada apenas de acordo com o que cada autor aborda sobre cada um dos assuntos propostos no conteúdo.

Palavras-chave: Meio Ambiente. Relações sociais. Comunidades locais.

\footnotetext{
${ }^{1}$ Mestrando em Desenvolvimento e Meio Ambiente pelo PRODEMA/UFS. Graduado em Geografia-Licenciatura pela Universidade Federal de Sergipe (Campus ItabaianaSE). Especialista em Biotecnologia e Meio Ambiente pela Faculdade Atlântico (Aracaju-SE). Membro do Grupo de Pesquisa GEOPLAN - Geoecologia e Planejamento Territorial (UFS/CNPq). E-mail: jadinho@live.com

${ }^{2}$ Mestrando em Desenvolvimento e Meio Ambiente pelo PRODEMA/UFS (Bolsista CAPES). Graduado em Geografia-Licenciatura pela Universidade Federal de AlagoasUFAL. E-mail: phellipecunha@hotmail.com
} 


\section{ABSTRACT}

This work was presented as a critical comparative review, attempts to address the relationship between society, nature and development elaborated by man. The approach will be given in two stages: the first addressing society and development, correlating ideas of authors from different eras, and the second, an approach between nature and development. The approach of the themes of nature is impersonal, portrayed only in accordance with what each author discusses about each of the matters raised in the content.

Keywords: Environment. Social Relations. Local Communities. 


\section{Introdução}

O homem, como ser social, se apropria da natureza a partir do trabalho, transformando-a as suas necessidades. É da natureza que o homem produz riquezas por meio do trabalho. O capitalismo é o principal responsável pelas diferentes maneiras de circulação do sistema. Em um mundo globalizado, é possível haver comunicação de uma parte qualquer do mundo à outra, sem que haja a necessidade de conhecimento geral daquele local. $\mathrm{Ou}$, então, é possível observar semelhanças entre culturas de diversos locais, porém com peculiaridades de cada uma das regiões.

Em relação ao Meio Ambiente, vale ressaltar as diversas conferências que acontecem pelo mundo, em busca da proteção e melhor aproveitamento dos recursos naturais, para que o homem possa viver em harmonia com o meio ambiente.

Alguns dos fatores relacionados aos atuais problemas de crescimento populacional estão relacionados à industrialização, poluição e diminuição dos recursos naturais disponíveis. Muito do que ocorre se deve ao fato de o homem não colocar limites às suas atividades de exploração desses bens naturais. É preciso que haja consenso de ideias no entendimento de que os recursos da natureza são finitos e em alguns casos de sensível cultivo. Segundo Alier:

\footnotetext{
Os compromissos morais com a natureza caracterizam a variante do ambientalismo aqui descrita como "culto ao silvestre", enquanto o interesse material pelos recursos e serviços ambientais proporcionados pelo meio natural para a subsistência humana caracteriza o ecologismo dos pobres (ALIER, 2007, p. 335).
}

É possível que haja crescimento sem que haja diminuição de recursos da natureza. Isso é possível, a partir de estudos de conscientização de uso racional desses recursos, de modo que respeite o tempo da própria natureza. Quanto mais cedo o homem entender esse tipo de argumento, mais cedo poderemos reverter o atual quadro, que vem por séculos, devastando tudo aquilo que a terra, a longo tempo, levou para construir.

\section{Sociedade e desenvolvimento}

As atividades cotidianas de uma sociedade baseiam-se em valores e liberdades os quais homens e mulheres cumprem seus papeis enquanto atores sociais. Para Overing (1999), o valor dado às atividades dos personagens, envolvidos em pequenas localidades indígenas da Amazônia, possui papel importante no contexto social relacionado ao 
coletivo, onde todos possuem privilégios e liberdades semelhantes. Assim,

\begin{abstract}
"O social", em seu sentido mais positivo, tal como expresso nas ações partilhadas e nas interações pessoais diárias, é provavelmente compreendido, por muitos povos da Amazônia, como um conjunto de meios potentes para se trabalhar ativamente contra o desenvolvimento de relações coercitivas. (OVERING, 1999, p. 87)
\end{abstract}

Overing (1999) descreve ainda que a sociedade indígena, da forma a qual é organizada, valoriza todas as habilidades e atividades praticadas por cada um, desde a caça ao cozimento dos alimentos, sem haver distinção entre a hierarquização na capacidade de realização de tais atividades.

\footnotetext{
Os Piaroa são um dentre os muitos povos da bacia amazônica cuja ênfase social está em alcançar uma certa qualidade de vida, a ser usufruída por meio de práticas cotidianas da vivência comunitária. Para eles, o supremo objetivo da vida social é manter alta a moral da comunidade. Este é um fim em si mesmo. Os objetivos políticos concernem à realização da harmonia nas relações diárias de produção e de comensalidade. (OVERING, 1999, p. 98)
}

O desenvolvimento econômico de um país está ligado à sua forma de governo. É comum ver a presença da denominada "fome coletiva" termo utilizado por Amartya Sen, em seu livro "Desenvolvimento como liberdade" - em países em que a ditadura é existente em sua forma de governo. Porém em nações onde há a democracia plena, a fome coletiva é, de certa forma, combatida, pois para que o líder daquele país chegue e permaneça no poder, necessita-se passar pelo processo de eleição, elaborando propostas e, após eleito, colocando-as em prática os projetos de combate a esse tipo de mal social, pois, caso não faça isso, logo será deposto ou não vencerá em um novo pleito eleitoral.

Há uma via de mão-dupla clara entre o dinheiro e o desenvolvimento, para Sen (2000), “o baixo nível e renda pode ser uma razão fundamental de analfabetismo e más condições de saúde, além de fome e subnutrição; e inversamente, melhor educação e saúde ajudam a auferir rendas mais elevadas" (SEN, 2000, p. 34). O contexto envolvendo pobreza e riqueza, é tratado por Sen (2000) como consequência da falta de liberdade gerada entre as classes devido a diversas privações como fome extrema e coletiva de populações, falta de liberdade e direitos civis básicos.

\footnotetext{
Afirma-se com certa frequência que a negação desses direitos ajuda a estimular o crescimento econômico e é "benéfica" para o desenvolvimento econômico rápido. Alguns chegaram a defender sistemas políticos mais autoritários - com negação e direitos civis e políticos básicos - alegando a vantagem desses sistemas na promoção do desenvolvimento econômico. Essa tese
} 
(frequentemente denominada de "tese de Lee", atribuída em algumas formas ao ex-primeiro-ministro de Cingapura, Lee Yuan Yew) às vezes é defendida por meio de algumas evidências empíricas bem rudimentares. (SEN, 2000, p. 30)

Comumente um país é mais desenvolvido de maneira econômica quando possui um poder político democrático com aberturas na economia que facilitem o acesso ao povo em diversos aspectos do que em países com regimes autoritários e severos.

Em "O mito do desenvolvimento econômico", Celso Furtado discorre acerca da estrutura dinâmica do capitalismo. No decorrer do livro, Furtado (2001) defende a correção dos erros e equívocos do sistema capitalista afirmando que o fenômeno do subdesenvolvimento só pode ser entendido através de análises históricas as quais levaram, em períodos de colonização, a devastação dos recursos naturais de diversos países. $\mathrm{O}$ autor define o subdesenvolvimento como resultado de uma conexão, surgida em certas situações históricas, entre um processo interno concentrador e um processo externo de dependência.

[...] a concepção de desenvolvimento de uma sociedade não é alheia à sua estrutura social, tampouco a formulação de uma política de desenvolvimento e sua implantação são concebíveis sem preparação ideológica. (FURTADO, 2001, p. 22).

Esse traço com a cópia de modelo de consumo produziria uma forma de convivência homogênea, porém em países subdesenvolvidos o consumo se concentra, na maior parte, nas mãos de poucas pessoas que consomem como se estivessem em países desenvolvidos.

A pobreza leva aos humanos, nela inseridos, à privação de diversas necessidades básicas como alimentação de qualidade, saúde e educação, instrumentos que para muitos, os mais abastados, não é uma mordomia, mas sim, bens necessários e simplórios do seu dia-a-dia.

Sobre o ecologismo dos pobres $^{3}$, termo utilizado por Joan Martinéz Alier, diz que:

Nos Estados Unidos, a justiça ambiental é um movimento a favor das chamadas "minorias", enquanto o ecologismo dos pobres é potencialmente um movimento não de minorias étnicas, mas sim de um seguimento majoritário em nível planetário. No ecologismo

\footnotetext{
${ }^{3} \mathrm{O}$ ecologismo dos pobres é uma importante e profunda contribuição para debates sobre meio ambiente, política e economia. Com a intenção explícita de auxiliar a estabelecer dois campos de estudos emergentes - ecologia política e economia ecológica -, Joan Martinéz Alier investiga as relações entre as duas áreas. Além disso, traça um panorama do aumento das tensões pelo acesso a recursos naturais e da relação entre progresso econômico e uso do meio ambiente.
} 
dos pobres, a relação entre as preocupações locais e as globais afirma-se com base em redes monotemáticas [...]. Os membros dessas redes superpõem-se parcialmente, através de programas ou de campanhas específicas de organizações confederadas globais [...]. (ALIER, 2007, p. 345).

É preciso incluir que essas privações não são inseridas apenas em países pobres. É notória em países declaradamente excludentes, como os Estados Unidos, a diferença de privações entre os brancos e os negros. Há grande discrepância de tratamento entre pessoas de cores diferentes, é possível, inclusive, analisar em dados estatísticos que, nos Estados Unidos, a expectativa de vida é maior entre os homens brancos do que para os negros, podendo, esses dados, caracterizarem as diferenças de qualidade de saúde e saneamento fornecida pelo governo a essas populações.

Apesar desse contraste entre os brancos e negros norte-americanos, os negros deste país ainda são mais ricos e com mais privilégios do que populações de diversos países mundo afora. Para Sen:

[...] argumentou-se que o desenvolvimento econômico do modo como o conhecemos pode, na realidade, ser danoso a um país, já que pode conduzir à eliminação de suas tradições e herança cultural. Objeções desse tipo são com frequência sumariamente descartadas com o argumento de que é melhor ser rico e feliz do que pobre e tradicional. (SEN, 2000, p. 47)

Demonstrar o quão é desenvolvido um país a partir das liberdades das pessoas, demonstra que "[...] não seja de modo algum desvinculada do processo de crescimento econômico e de acumulação de capital físico e humano, seu alcance e abrangência vão muito além dessas variáveis" (SEN, 2000, p. 49).

\section{Natureza e desenvolvimento}

O desenvolvimento das sociedades se dá pelo aprimoramento de sua organização social e de sua condição de vida por meio de processos que permitam, além do avanço científico e tecnológico, melhorias no âmbito do uso sustentável dos recursos disponibilizados pela natureza.

Há certa confusão de entendimento quando se relaciona o desenvolvimento com crescimento. Confusão propositada que tem a finalidade de ofuscar os principais propósitos do capitalismo que, para atenderão interesse da camada dominante e resistir como sistema, atribui um "crescimento" econômico que agrava a exploração das classes 
trabalhadoras e explora os recursos naturais para além da sustentabilidade.

Segundo Thompson (1998) não é possível explicar as populações naturais sem vincular à economia moral. A economia é tão importante quanto a religião e a cultura, sendo, dessa forma, impossível pensar em costumes de um povo sem vinculá-los aos territórios neles inseridos. No desenvolver de períodos pode até ser observados que alguns costumes desaparecem, mas aqueles com utilidade no dia a dia permanecem e resistem ao tempo. Esses tipos de costumes fomentam na necessidade de aprimorar técnicas passada entre gerações a fim de ampliar os conhecimentos e repassar para futuras gerações.

[...] pela divisão de trabalho, supervisão do trabalho, multas, sinos e relógios, incentivos em dinheiro, pregações e ensino, supressão das feiras e dos esportes - formaram-se novos hábitos de trabalho, impôs-se uma nova disciplina de tempo. (THOMPSON, 1998, p. 297)

Thompson (1998) diz ainda que não é possível explicar as populações naturais sem vincular à esse tipo de economia. A modernidade aponta-se na destruição das culturas locais, porém a resistência, atribuída ao trabalho, é parte da vida onde, ao mesmo tempo, vivencia realizações propostas por seus personagens na manutenção de costumes e tradições.

É possível perceber que há grande aversão em relação à analogia entre riquezas naturais e poder aquisitivo. Para Drummond (2002), locais ricos em recursos naturais são localidades com populações mais pobres. Há estudos que indicam maior viabilidade econômica, às populações dessas localidades, para que produzam alimentos para sua subsistência, ao invés de comercializá-los ou adquiri-los de terceiros.

Essa percepção fundamenta-se na premissa que riqueza natural e riqueza social andam juntas (ou, numa postura normativa, que ambas "devem" andar juntas). [...] Não faltam, igualmente, argumentações teóricas e estudos empíricos. Alguns, formulados há décadas, colocaram em dúvida esse pressuposto e testaram-no como hipótese de investigações científicas, chegando a resultados que o refutam. (DRUMMOND, 2002, p. 2)

O foco desse estudo feito por Drummond (2002) foram as regiões extrativistas, apenas os empreendimentos dedicados à exclusiva retirada de recursos naturais sem "manipulação produtiva ou processamento industrial” (DRUMMOND, 2002, p. 2).

A natureza já estava sendo destruída antes da modernidade, o mito de que o homem tratava melhor a natureza antes de nossa época é desfeito por 
Keith Thomas (1988), em seu livro "O homem e o mundo natural", no qual afirma que não havia um apreço à conservação da natureza, sendo que ela só veio ter importância após o início do período moderno.

Para Thomas (1988) a força da reforma protestante durante o século XVI intensificou o olhar acerca da natureza. Foi nessa época que o homem defendia por si próprio como um ser sublime, idêntico à imagem de Deus, considerando a si mesmo como o centro do mundo. Com isso, a ciência surge para discutir sobre o que está contido na natureza, com a finalidade de distinguir o que é bom ou não ao próprio homem. O homem tratava a si mesmo como ser superior a qualquer criatura, pois possuía consciência e conhecimento religioso, sendo os animais, desse modo, seres desprovidos de alma, verdadeiras bestas.

Ainda segundo Thomas (1988) no período moderno, com o desenvolvimento da ciência, há a negação dos conceitos religiosos, dando à ciência autonomia em seus estudos, possibilitando dessa maneira criar um novo olhar acerca do próprio homem. Os animais deixam de ser considerados bestas, o cultivo de árvores e plantas passa a ser um negócio, como produção de matéria-prima, em suma, a fauna e a flora passam também a ser importantes por si só. "A aceitação explícita da ideia de que o mundo não existe somente para o homem pode ser considerada como uma das grandes revoluções do moderno pensamento ocidental [...]" (THOMAS, 1988, p. 198).

Segundo Drummond, para os pensadores da escola "cepalina"״é praticamente impossível que haja desenvolvimento e prosperidade em regiões que a principal fonte de geração e capital é a produção de produtos primários, sobretudo relacionados ao extrativismo.

Indo de contramão a esses fatos, a urbanização começa a se intensificar, degradando os espaços naturais, porém, há uma preocupação em relação à melhoria na qualidade de vida, possibilitando dessa maneira uma maior preocupação com a qualidade do ar, água e diversos outros fatores dependentes da conservação do espaço natural.

4 A CEPAL - Comissão Econômica para a América Latina, criada em 1948 por economistas, políticos e sociólogos latino-americanos, caracteriza-se por ter desenvolvido os fundamentos teóricos da ideologia desenvolvimentista, que via na industrialização, única forma de libertação dos países subdesenvolvidos, da sua situação de pobreza e dependência externa. Assim, a industrialização é vista como caminho para o desenvolvimento. A Teoria Cepalina visa explicar o atraso da América Latina (periferia), em relação aos países desenvolvidos (centrais), e encontrar as formas de superá-lo.

Revista Ambivalências •ISSN 2318-3888•V1・N.2・p. $145-155 \bullet J u l-D e z / 2013$. 
Para Diegues (2000), o conhecimento científico e seus saberes são tão importantes quanto os saberes locais. Essa ação dialética, denominada etnoconservação ${ }^{5}$, valoriza o saber popular e o religioso para dar base a novas práticas de produção. As formas de manejo ambiental devem respeitar, em primeiro lugar, os saberes baseados na experiência das populações locais. Assim, na compreensão do aludido autor,

\begin{abstract}
Para esse manejo científico, exige-se, por exemplo, o "conhecimento profundo do ecossistema", mesmo quando se sabe que as informações científicas necessárias não são facilmente disponíveis e que os limites dos ecossistemas variam segundo a formação de cada cientista, seja ele biólogo, pedólogo, botânico, etc. (DIEGUES, 2000, p. 34).
\end{abstract}

Uma nova aliança, entre a política e o social, é repensada a luz da pauta do planejamento ambiental com a finalidade de melhorias no manejo de recursos naturais. A etnoconservação representa, de fato, uma democratização da ciência, onde os saberes e experiências de um povo são tratados com valor face à ciência, por eles serem também, em vários aspectos, certo tipo de ciência, a ciência do concreto.

\title{
Considerações finais
}

O meio ambiente está ameaçado pelo alto consumo. Para Alier (2007), ainda não existe um índice para calcular a insustentabilidade, é preciso haver estudos no campo transdisciplinar para permitir a elaboração de indicadores para possibilitar uma avaliação integrada num ponto de vista de diversos critérios.

A crescente degradação do meio ambiente e a exaustão dos recursos naturais acarretados, sobretudo pela ação antrópica de práticas produtivas indiscriminadas sem a observação de que os recursos naturais podem se extinguir, leva a uma preocupação global através de pesquisas relacionadas a esta temática, com a intenção de reestabelecer os recursos já degradados e preservar os que ainda conseguem sobreviver neste sistema capitalista de produção que visa a lucratividade imediata sem o respeito aos componentes ambientais.

É nesse contexto que há uma necessidade de pesquisas relacionadas ao tema abordado, principalmente para prevenir impactos ambientais e para minimizar as degradações já existentes.

\footnotetext{
${ }^{5}$ Antônio Carlos Diegues trabalha a etnoconservação como forma de proteção das espécies da flora e da fauna e que é questão essencial para a sobrevivência da própria humanidade.
} 
$\mathrm{Na}$ atual economia de mercado, o homem é incentivado a pensar em necessidades, as quais o incentiva ao consumo de forma desenfreada. A indústria entra nesse contexto como ator principal para a supressão dessas novas, ou não, necessidades humanas.

Os países subdesenvolvidos encontram-se, em geral, sob influência econômica e política de países industrializados, estes dominam sua economia e sugam os recursos (matérias-primas, alimentos) que há naqueles países, em função de seu suprimento. O espaço econômico de um país não deve se restringir apenas ao mercado interno, ou seja, há países que extravasa as suas fronteiras influenciando a economia de outras nações. A configuração de um mercado mundial, formado a partir de fortes concentrações monopólicas que levam, inclusive, à aliança de algumas nações e à confrontação entre grupos delas na luta pelo domínio do planeta.

É preciso que haja mudança radical, no que rege o modelo de civilização atual, para que os padrões insustentáveis de desenvolvimento sejam modificados para que possa haver desenvolvimento sem perda de regalias, às quais o homem já está acostumado, com uso sustentável dos recursos disponibilizados pela natureza.

\section{Referências}

ALIER, Joan Martínez. O ecologismo dos pobres: conflitos ambientais e linguagem de valoração. São Paulo: Contexto, 2007 (pág. 89-118; pág. 119-144; da pág. 333-357).

DIEGUES, Antônio Carlos. Etnoconservação da natureza: enfoques alternativos. In: (org.) Etnoconservação: novos rumos para a proteção da natureza nos trópicos. SãoPaulo: Annablume/NUPAUB, 2000. p. 01-46.

DRUMMOND, José Augusto.Natureza rica, povos pobres? - questões conceituais e analíticas sobre o papel dos recursos naturais na prosperidade contemporânea. In: Revista Ambiente\& sociedade. Campinas, n.10, pp. 45-68, 2002. <Disponívelem: http://www.scielo.br/pdf/asoc/n10/16885.pdf>

FURTADO, Celso. O mito do desenvolvimento econômico. Paz e terra.

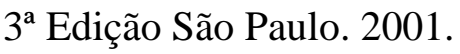


OVERING, Joanna. Elogio do cotidiano: a confiança e a arte da vida social em uma comunidade amazônica In: - Estudos de Antropologia Social, vol. 5, n. 1, p. 81-107, Rio deJaneiro, abril/1999. Disponível em:Revista Manahttp://www.scielo.br/pdf/mana/v5n1/v5n1a04.pdf

SEN, Amartya. Desenvolvimento como liberdade. São Paulo: Companhia das Letras, 2000.

THOMAS, Keith. O homem e o mundo natural: mudanças de atitudes em relação às plantas e aos animais(1500-1800). São Paulo: Companhia das Letras, 1988.

THOMPSON, E. P.Tempo, disciplina de trabalho e capitalismo industrial. In.: __ Costumes em comum. Trad. Rosaura Eichemberg. Editora Schwarcz, São Paulo: 1998.p. 267 - 304. 